\title{
Rancang Bangun Aplikasi Pembelajaran Sistem Operasi Windows Pada Matakuliah Sistem Operasi Di STMIK Indonesia Padang Berbasis Multimedia Interaktif
}

\author{
Nelfira ${ }^{1}$, Diana Silvia ${ }^{2}$ \\ ${ }^{1,2}$ STMIK Indonesia Padang \\ Jl. Khatib Sulaiman dalam No.1 Padang
}

\begin{abstract}
Penyampaian materi pembelajaran sistem operasi di STMIK Indonesia Padang masih dalam bentuk deskribsi manual, sehingga dosen sistem operasi merasakan kesulitan menyampaikan materi praktek kepada mahasiswa karena deskripsi teks dan gambar tidak dapat mewakili materi pembelajaran sistem operasi windows. Untuk mengatasi masalah ini dibutuhkan media pembelajaran sistem operasi yang dapat membantu dosen dalam menyampaikan materi perkuliahan sistem operasi dengan mudah. Aplikasi Interaktif Pembelajaran Sistem Operasi Windows (AIPSOW) berbasis multimedia merupakan sebuah sistem pembelajaran bantuan komputer, yang menerangkan materi pembelajaran sistem operasi, baik itu gambar, cara kerja atau kegunaannya. Aplikasi yang digunakan pada penelitian ini yaitu menggunakan AutoPlay Media Studio dengan bahasa pemrograman Lua. Aplikasi ini menjadi sarana pembelajaran dalam mengenali dan mengetahui cara penggunaan windows 7 dengan menggabungkan unsur teks, gambar, video (gambar bergerak), animasi, tombol interaktif, musik dan suara sehingga lebih efektif.
\end{abstract}

Kata Kunci : AIPSOW, Multimedia, Sistem Operasi, Pembelajaran

\section{LATAR BELAKANG PENELITIAN}

Kemajuan ilmu dan teknologi yang berkembang pesat pada saat ini, turut membantu manusia dalam memasuki zaman baru di era teknologi yang diciptakan untuk memperingan beban aktifitas di dalam kehidupan sehari-hari serta membantu kita dalam memberikan informasi yang cepat, tepat, serta akurat tentang pembelajaran khususnya pada proses belajar mengajar baik pada pendidikan formal maupun non-formal.

Aplikasi multimedia memungkinkan pemakai komputer untuk memperoleh output dalam bentuk yang lebih menarik dibandingkan dengan media media cetak atau majalah. Salah satu bentuk media pembelajaran yaitu multimedia interaktif yang merupakan penggabungan komputer dengan multimedia. Multimedia interaktif dapat memberikan kemudahan bagi pengguna untuk memperoleh informasi yang lebih jelas, karena penyampaian informasinya ditampilkan secara multimedia (banyak media), sehingga lebih mudah dimengerti dan lebih menarik.

Mata kuliah sistem operasi merupakan salah satu mata kuliah wajib yang ada di STMIK Indonesia Padang. Berdasarkan wawancara yang sudah dilakukan dengan salah satu dosen yang mengajar mata kuliah sistem operasi, dosen tersebut mengatakan bahwa terdapat kesulitan dalam menyampaikan bahan ajar sistem operasi pada mata kuliah sistem operasi, karena terdapat beberapa materi yang tidak cukup hanya dijelaskan dengan lisan dan tulisan saja. Oleh sebab itu, diperlukan sebuah media yang mampu menjelaskan dan menggambarkan materi secara detail tidak hanya melalui gambar dan teks saja, akan tetapi juga dalam bentuk video simulasi. 
Dalam hal ini yang dimaksud adalah pembelajaran sistem operasi windows. Berdasarkan permasalahan tersebut, skripsi ini diberi judul "Rancang Bangun Aplikasi Pembelajaran Sistem Operasi Windows Pada Mata Kuliah Sistem Operasi di Stmik Indonesia Padang Berbasis Multimedia Interaktif".

\section{STUDI PUSTAKA}

\subsection{Sistem Operasi}

Menurut Abdul Kadir (2013:164)

Sistem operasi adalah program terpenting dari program-program yang terdapat dalam sistem komputer. Sistem operasi dapat dianggap sebagai program kontrol yang bertugas untuk menjalankan programprogram lain yang ada di dalam komputer. Dalam hal ini sistem operasi berada di tengah-tengah antara program atau aplikasi dan perangkat keras, dan bertindak sebagai pembagi sumber daya (resource allocator) yang mengatur penggunaan sumber daya, seperti siklus CPU, memori, ruang penyimpanan disk dan alat-alat input dan output.

\subsection{Macam-macam Sistem Operasi}

Menurut Abdul Kadir (2013:165) Banyak sekali macam sistem operasi saat ini di antaranya Microsoft Windows, Linux, MacOS, BeOS, Sun Solaris, Novell Netware, Unix, dan lain-lain. Namun, sistem operasi yang popular saat ini adalah Microsoft Windows dan Linux sebagai pesaingnya.

\subsection{Fungsi Sistem Operasi}

Menurut Abdul Kadir (2013:165) Sistem Operasi mempunyai tiga fungsi utama yaitu manajemen proses, manajemen sumber daya, dan manajemen data.
a. Manajemen proses mencakup penyiapan, penjadwalan, dan pemantauan proses pada komputer.

Proses adalah program yang sedang dijalankan.

b. Manajemen sumber daya berkaitan dengan pengendalian terhadap pemakaian sumber daya dalam sitem komputer yang dilakukan oleh perangkat lunak sistem ataupun perangkat lunak aplikasi yang sedang djalankan pada komputer.

c. Manajemen data berupa pengendalian terhadap data masukan atau keluaran, termasuk dalam hal pengalokasian dalam peranti penyimpan sekunder maupun dalam memori utama.

Selain ketiga fungsi tersebut, sitem operasi umumnya juga mempunyai sarana untuk mengelola keamanan. Ciri sistem operasi mempunyai fasilitas manajemen kemanan adalah mengaharuskan pemakai memasukan nama pemakai dan password(kata rahasia) sebelum bisa mengakses komputer.

\subsection{Windows}

Menurut Dony Ariyus (2010:137) "Windows adalah salah satu software sistem operasi yang dikeluarkan oleh perusahaan Microsoft Inc. Microsoft Windows adalah software sistem informasi yang paling populer untuk para pengguna PC. Tampilan Windows yang "user friendly" membuatnya menjadi pilihan utama."

Menurut Dony Ariyus (2010:137) sejarah Windows dimulai dari DosShell for Dos 6 buatan miecrosoft dan inginnya Microsoft bersaing terhadap larisnya penjualan apple macintosh yang menggunakan GUI, Microsoft menciptakan Windows 1.0. Nama ini berasal dari kelatahan karyawan miscrosoft yang menyebut nama aplikasi tersebut sebagai program windows (jendela program). Versi dari MS-Windows yang sudah dirilis sebagai berikut:

a. 16-bit, berjalan di atas MS-DOS

1) November $1985:$ windows 1.0 
2) 22 Mei $1990:$ Windows 2.0

3) Agustus 1992 : Windows 3.0

4) Oktober 1992 : Windows for Workgroups 3.1

5) November 1993 : Windows for workgroup 3.11

b. Hibrida (16-bit/32-bit), berjalan tanpa MS-DOS.

1) 24 Agurtus 1995 : Windwos 95 (Versi : 4.00.1950)

2) 25 juni 1998 : Windows 98 (Versi: 4.1.1998)

3) 5 Mei 1999 : Windwos 98 second edition (Versi: 4.1.222)

4) 19 Juni 2000: Windows Millenium Edition

c. Berbasis kornel Windows NT

1) Agustus 1993 : Windows NT 3.1

2) September $1994:$ Windows NT 3.5

3) Juni 1995 : Windows NT 3.51

4) 29 Juli $1996:$ Windows Nt 4.0

5) 17 Februari 2000 : Windows 2000 (Versi : NT 5.0.2195)

6) 2002: Windows XP (Versi : NT 5.2.3790)

7) 2007 : Windows vista (Versi 6.0 Build 6000)

d. Versi yang akan datang

1) 2007-2008: Windows Server 2008 (versi 6.1)

2) 2010-2012: Windows "Vienna".

\subsection{Definisi Perangkat Lunak}

Menurut Roger S. Pressman (2015:5) Perangkat lunak atau software adalah"perintah (program komputer) yang bila dieksekusi memberikan fungsi dan unjuk kerja seperti yang diinginkan, struktur data yang memungkinkan program memanipulasi informasi secara proporsional. Dokumen yang menggambarkan operasi dan kegunaan program".

\subsection{Defenisi Multimedia}

Menurut Suyanto (2005:20) Multimedia berasal dari kata multi yang berarti banyak atau lebih dari satu media antara lain berupa gambar, tulisan (text), foto, video dan audio. Multi dalam bahasa Latin berarti banyak atau berbagai, medium di dalam bahasa Latin berarti perantara atau suatu perantara yang digunakan untuk menghantar atau menyampaikan sesuatu seperti surat kabar, majalah atau televisi. Multimedia dapat juga diartikan gabungan teks, grafik, bunyi, video dan animasi yang menghasilkan prestasi dan interaktif yang tinggi.

Definisi lain dari multimedia adalah pemanfaatan komputer untuk membuat dan menggabungkan teks, grafik, audio, gambar gerak (video dan animasi) dengan menggabungkan link dan tool yang memungkinkan pemakai melakukan navigasi, berinteraksi, berkreasi dan berkomunikasi. Multimedia merupakan media periklanan yang unik dan sangat kuat karena mengandung elemen penglihatan, video dan suara yang dapat dikombinasikan dengan strategi kreatif untuk menghasilkan daya tarik dan eksekusi iklan.

\section{ANALISA DAN HASIL}

1.1. Analisa Sistem Yang Sedang Berjalan

Proses penyampaian media pembelajaran mata kuliah Sistem Operasi yang sedang berjalan pada STMIK Indonesia Padang dapat diuraikan sebagai berikut:

1. Melaksanakan proses belajar mengajar menggunakan bahan ajar buku, papan tulis dan slide presentasi.

2. Melakukan sosialisasi instalasi pada mata kuliah sistem operasi hanya berupa teori.

3. Menyusun materi pembelajaran sesuai dengan bahan ajar yang sudah ditentukan

\section{Fungsional Aplikasi}

Aplikasi pembelajaran sistem operasi ini memiliki kemampuan sebagai berikut : 
a. Menyajikan pembahasan dasar berupa pengenalan sistem operasi, macammacam sistem operasi, windows dan cara menggunakan windows.

b. Aplikasi ini tidak hanya bisa digunakan dikampus saja, dengan menggunakan CD-interaktif mahasiswa dapat menggunakan kembali di rumah.

c. Setiap pembahasan yang disajikan disertai dengan gambar, tulisan dan animasi menarik yang berkaitan dengan pembahasan tersebut

\section{A. Hasil Aplikasi}

Setelah melakukan serangkaian tahapan perencanaan, analisis, perancangan dan desain, maka didapatkan suatu aplikasi yang sesuai dengan perancangan dan analisis sebelumnya. Aplikasi pembelajaran sistem operasi windows 7 ini dalam penerapannya perlu dilakukan pengujian agar sesuai dengan perencanaaan, desain dan tujuan dari pokok permasalahan sebelumnya.

\section{Tampilan Loading}

Saat pertama dijalankan, aplikasi akan menampilkan halaman loading. Setelah selesai, maka akan tampil halaman petunjuk aplikasi. Tampilan loading ini muncul sebagai pembukaan dan persiapan user untuk menuju ke halaman petunjuk aplikasi. Halaman loading juga menampilkan nama pembuat produk sebagai bagian dari hak cipta suatu produk.

Tampilan halaman loading Aplikasi pembelajaran sistem operasi windows 7 dapat dilihat pada gambar pada halaman berikut:

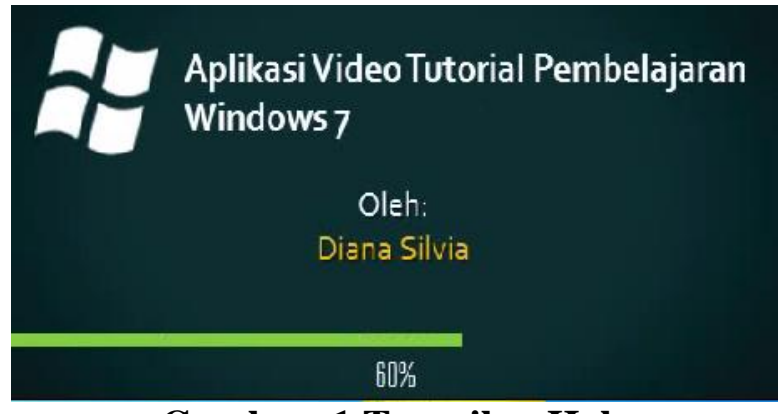

Gambar .1 Tampilan Halaman Loading

\section{Tampilan Petunjuk Aplikasi}

Halaman petunjuk aplikasi akan langsung dipanggil setelah aplikasi dijalankan dan melewati loading $100 \%$, pada halaman ini berisi cara menjalankan aplikasi dan sedikit informasi mengenai isi dari aplikasi itu sendiri. Tampilan halaman petunjuk aplikasi pembelajaran sistem operasi windows 7 dapat dilihat pada gambar berikut:

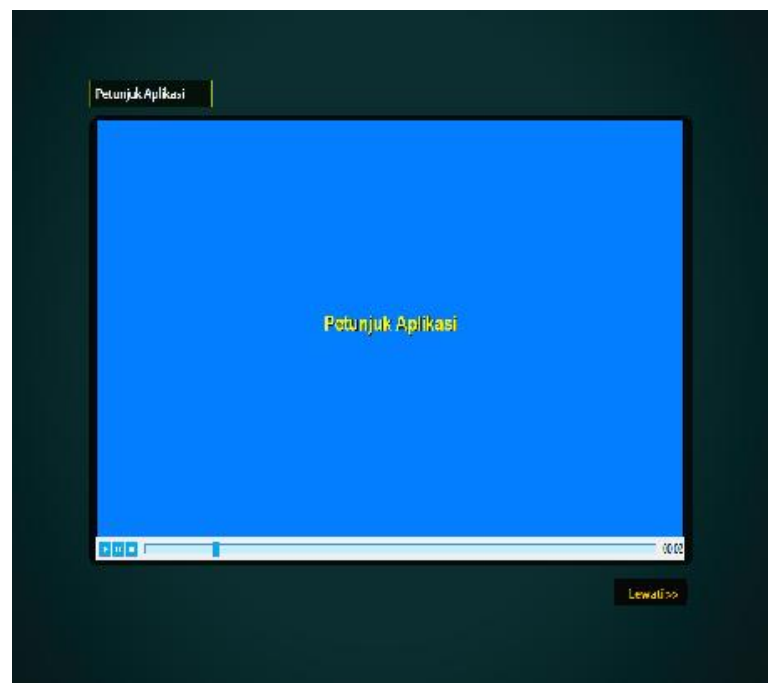

Gambar 2 Tampilan Halaman Petunjuk Aplikasi

\section{Tampilan Halaman Utama}

Halaman menu utama ini berisi menu tentang sistem operasi windows 7 , tentang windows, video tutorial, pembuat aplikasi, uji wawasan, menu Exitdan musik kontrol, pada halaman ini ditampilkan juga dialog 
selamat datang untuk memberikan sedikit penjelasan tentang pemakaian aplikasi terutama tentang halaman utama. Halaman akan ditampilkan sesuai dengan menu yang dipilih. Halaman utama dapat dilihat pada gambar berikut:

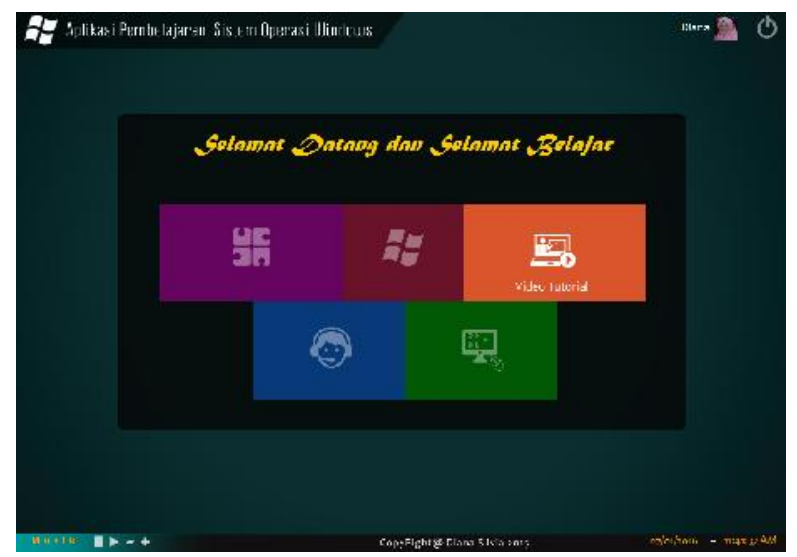

Gambar.3 Tampilan Halaman Utama

\section{Tampilan Halaman Video Tutorial}

Halaman video tutorial terdapat 16 (enam belas) submenu yang ditempatkan di sebelah kiri dari aplikasi dan konten sebelah kanan dari submenu, setiap submenu yang dipilih akan menampilkan konten sesuai pilihan yang berisi video tutorial. Video yang ditampilkan dibagi menjadi 16 pertemuan sesuai dengan jumlah pertemuan mata kuliah sistem operasi windows 7 , pada setiap video akan diberikan juga penjelasan lebih lengkap berupa teks dalam video yang bertujuan untuk memudahkan pengguna memahami isi video tutorial. Halaman video tutorial dapat dilihat pada gambar berikut:

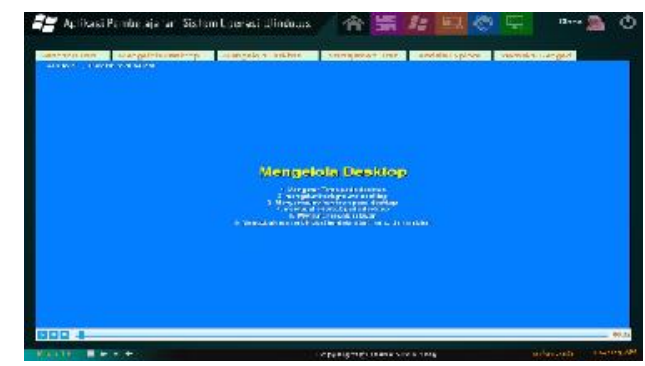

Gambar .4 Tampilan Halaman Video Tutorial

\section{Tampilan Dialog Materi}

Dialog materi ini menampilkan materi tentang sistem operasi dan penjelasan tentang windows sebagai materi pelengkap dalam aplikasi ini, materi ini disajikan agar pengguna lebih mengetahui tentang sistem operasi itu sendiri terlebih dahulu sebelum mempelajari cara penggunaannya. Seperti misalnya dialog sekilas sistem operasi dan tentang windows 7 . Tampilan dialog sekilas sistem operasi dan tentang windows 7 dapat dilihat pada gambar berikut:

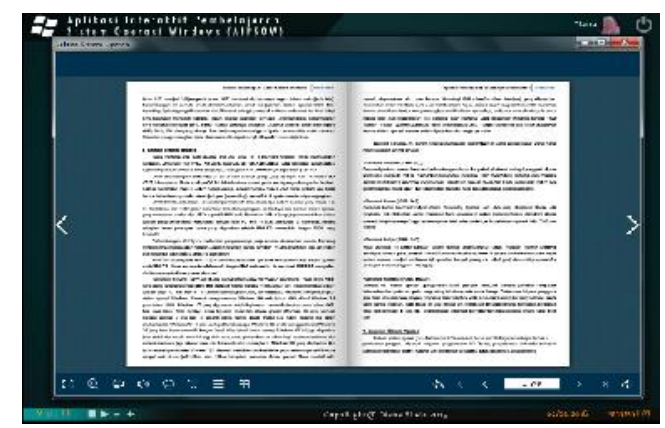

Gambar 5. Tampilan Dialog Materi Sekilas Sistem Operasi

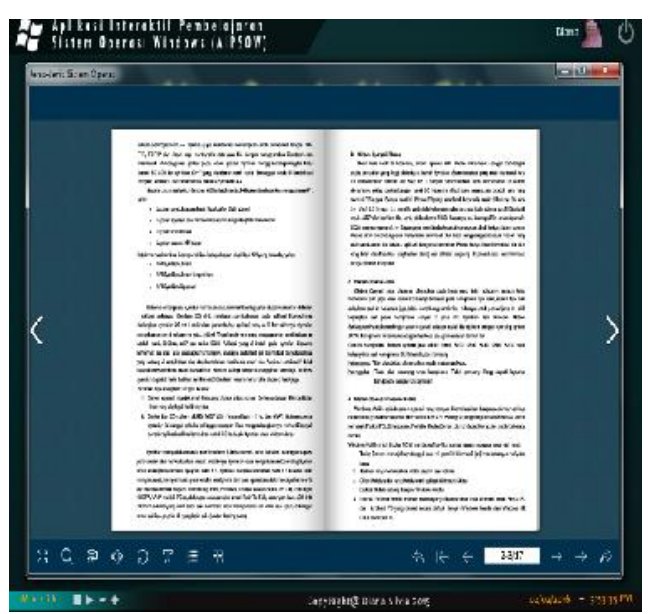

Gambar 6 Tampilan Dialog Materi Tentang Windows

\section{Tampilan Dialog Instalasi}

Dialog instalasi windows ini berisi video penjelasan cara menginstal windows 7 yang disertai juga dengan teks penjelasan. Tampilan dialog instalasi windows dapat dilihat pada gambar berikut: 


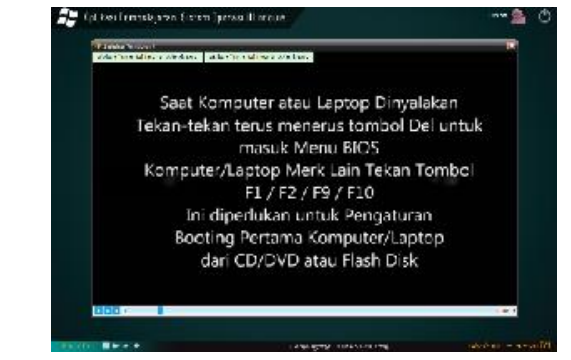

Gambar 7 Tampilan Dialog Video Instalasi

Selain menyajikan cara instalasi windows dengan berupa video, juga disertakan cara instal manual yang disajikan dalam dialog yang sama. Tampilan instalasi windows manual dapat dilihat pada gambar berikut:

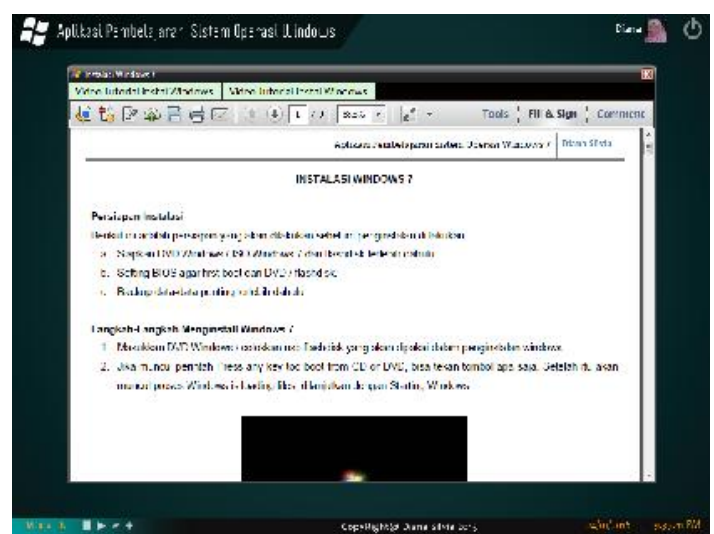

\section{Gambar 8Tampilan Dialog Instalasi Manual}

\section{Tampilan Dialog Uji Wawasan}

Dialog uji wawasan berisi soal pilihan ganda 30 pertanyaan dengan waktu menjawab 10 menit, soal ini dimaksudkan agar pemakai aplikasi dapat memastikan materi yang disampaikan dalam aplikasi ini terkuasai dengan baik. Diakhir pertanyaan akan ditampilkan juga hasil penilaian dalam bentuk angka dan keterangan. Tampilan dialog dapat dilihat pada gambar pada halaman berikut:

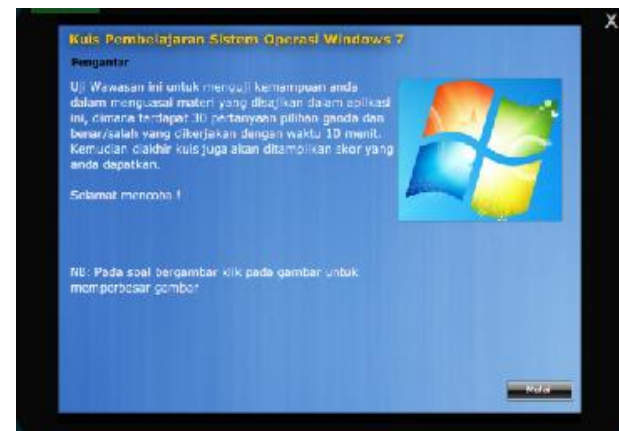

Gambar 9 Tampilan Dialog Uji Wawasan

\section{Tampilan Dialog Pembuat Aplikasi}

Dialog pembuat aplikasi ini berisi data diri penulis sebagai bagian dari hak cipta pembuatan aplikasi yang akan dikonsumsi oleh masyarakat luas, sehingga menghindari pengakuan-pengkuan dari pihak lain. Tampilan dialog tentang penulis dapat dilihat pada gambar berikut:

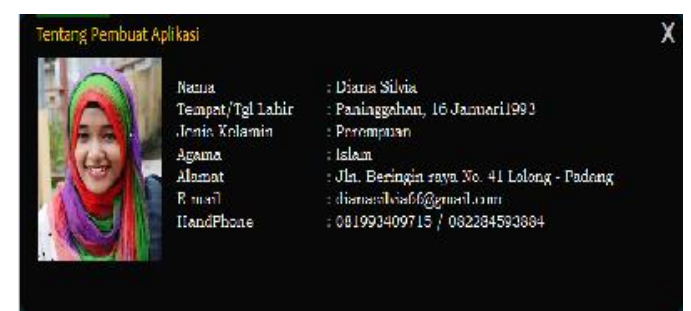

Gambar 10 Tampilan Dialog Pembuat Aplikasi

\section{Tampilan Keluar}

Tampilan keluar merupakan yang muncul saat tanda power dengan warna putih pada sudut kanan atas diklik, akan ada 2 (dua) tombol dengan teks Keluar dan Sembunyikan serta tombol $X$ untuk menutup dialog pilihan, apabila pilih Keluar maka akan keluar dari aplikasi, apabila pilih Sembunyikan maka aplikasi akan disembunyikan ke taksbar. Tampilan keluar dapat dilihat pada gambar berikut:

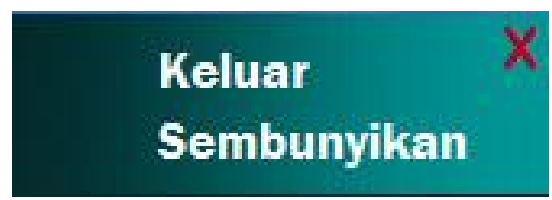

Gambar 11 Tampilan Keluar 


\section{B. Evaluasi Aplikasi}

Dari pembuatan aplikasi ini, dibuat melalui tiga tahap, yaitu melalu tahap input lalu kemudian proses dan akhirnya output. Gambar analisis aplikasi ditunjukan pada gambar berikut:

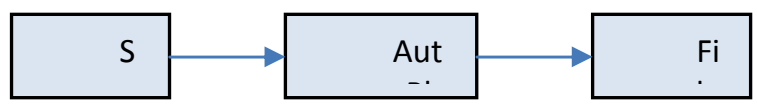

\section{Gambar 12Analisis Aplikasi}

\section{Input}

Tahap ini dilakukan pengumpulan data yang akan dimasukan dan dibahas, yang didapat dari berbagai macam sumber yang ada, pengumpulan ini dimaksudkan agar tercapainya tujuan pembuatan aplikasi ini.

\section{Proses}

Tahap ini dilakukan perancangan dengan memasukkan obyek-obyek multimedia kedalam project aplikasi, kemudia didesain dengan sedemikian rupa agar bisa menjadi aplikasi yang menarik. Obyek-obyek yang akan dipakai dalam aplikasi ini berupa text, image, maupun vidoe, Gambaran proses ditunjukan pada gambar berikut:

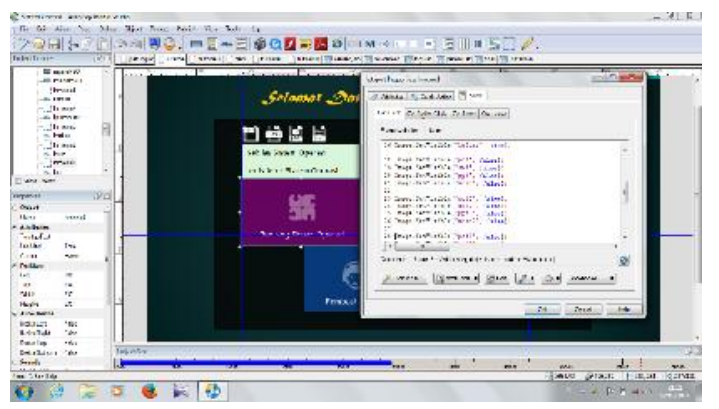

Gambar 13 Proses

\section{Output}

Setelah melakukan dua tahap diatas kemudian masukan yang telah di proses direalisasikan menjadi output yang berupa aplikasi multimedia untuk memberikan pembelajaran tentang sistem operasi windows 7. Gambar output ditunjukan pada gambar di halaman berikut:

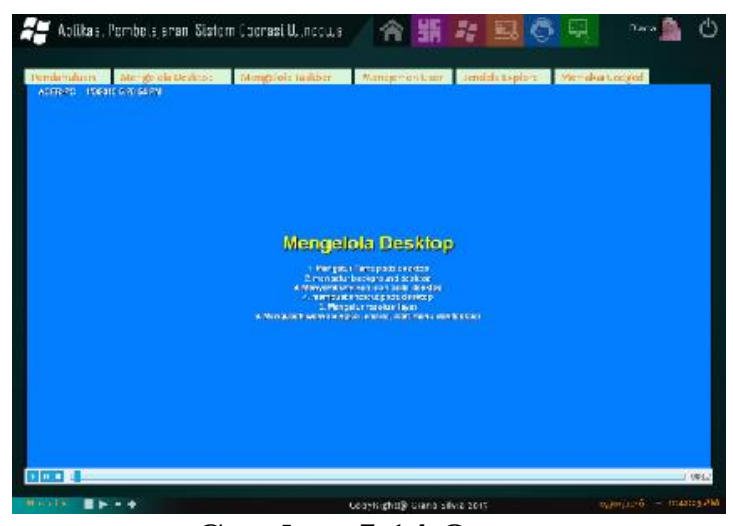

Gambar 5.14 Output

Berdasarkan analisis dan hasil dalam perancangan serta pembuatan aplikasi pembelajaran sistem operasi ini, dapat diambil kesimpulan dan saran-saran yang berhubungan dengan aplikasi ini.

\section{KESIMPULAN}

Berdasarkan analisis yang telah dilakukan serta hasil yang telah diperoleh selama perancangan dan pembuatan, maka dapat ditarik kesimpulan sebagai berikut:

1. Menjadikan Aplikasi ini sebagai media pembelajaran interaktif untuk pembelajaran yang lebih efektif.

2. Aplikasi ini dibuat dengan menggabungkan obyek-obyek multimedia seperti teks, gambar, animasi, suara dan video agar dapat mewakili bahan ajar yang akan disampaikan baik itu materi maupun simulasi praktek.

3. Aplikasi menjadi sarana pebelajaran dalam mengenali dan mengetahui cara menggunakan sistem operasi windows 7 pada mata kuliah sistem operasi di STMIK Indonesia.

\section{SARAN}

plikasi ini kedepannya tidak menutup kemungkinan akan mengalami perkembangan dan perbaikan untuk menjadi 
lebih baik, ada beberapa saran yang dapat disaampaikan, yaitu:

1. Aplikasi pembelajaran sistem operasi ini masih sebatas menjelaskan tentang satu sistem operasi yaitu windows, disarankan kepada pengembang untuk membuat aplikasi pembelajaran sistem operasi secara lengkap.

2. Disarankan agar obyek-obyek yang dimasukkan dalam aplikasi terlebih dahulu melalui proses editing, sehingga sesuai kebutuhan dari aplikasi yang akan dibuat mengikuti perkembangan desain yang ada.

3. Diharapkan pengembangan lebih lanjut pada aplikasi ini, yaitu berupa penambahan animasi dalam bentuk 3D, tema tampilan yang disesuaikan dengan pengguna dan membuat dengan software flash agar menghasilkan keluaran yang lebih beragam serta bisa dipublikasikan kedalam website.

\section{DAFTAR PUSTAKA}

Ariyus, Dony. (2010). Sistem Operasi. Yogyakarta: Andi Offset.

Hamim Tohari. (2014). Analisa serta Perancangan Sistem Informasi melalui Pendekatan UML. Yogyakarta: Andi Offset.

Ilham Eka Putra. (2013). Konsep dan Aplikasi Multimedia. Yogyakarta: Publisher

IndigoRose. n.d About AutoPlay Media Studio(http://www.autoplay.org/over view-autoplay-media-studio/,diakses tanggal 16 Desember 2015).

IndigoRose. n.d Features of AutoPlay Media Studio.

http://www.indigorose.com/products/ autoplay-media-studio/features/, diakses tanggal 16 Desember 2015.

Kadir, Abdul. (2013). Pengantar Teknologi Informasi. Yogyakarta: Andi Offset.

Kusrianto. (2007). Pengantar Desain Komunikasi Visual. Yogyakarta: Andi Offset.

MADCOMS. (2010). Sistem Operasi Modern. Yogyakarta: Andi Offset.

Sari, Riri Fitri. (2005). Sistem Operasi Modern. Yogyakarta: Andi Offset.

Suyanto. (2005). Alat Bantu Meningkatkan Keunggulan Bersaing. Yogyakarta.: Andi Offset

Roger S.Pressman. (2012). Rekayasa Perangkat Lunak. Yogyakarta: Andi. Tinarbuko. (2009). Semiotika Komunikasi Visual.Yogyakarta: Jalasutra. 